\title{
O supereu em Freud e Lacan: da moralidade à amoralidade, uma gula estrutural*1
}

Superego in Freudian and Lacanian thoughts: from morality to amorality, a structural gluttony

\author{
Breno Ferreira Pena*2 \\ Jacqueline de Oliveira Moreira*3 \\ Andréa Máris Campos Guerra*4
}

Neste artigo buscou-se demarcar uma formulação sobre o supereu, apoiada na obra de Freud e no ensino de Lacan, que destacasse seu modo de funcionamento, no qual prevalece sua gula estrutural, seu estatuto Real e seu estatuto de instância psíquica capazes de obrigar o sujeito a gozar. Traçar as vicissitudes teóricas e clínicas do supereu por um percurso histórico que leva do excesso de moralidade descrito por Freud à amoralidade desvelada por Lacan, evidencia sua gula de gozo como o que lhe confere uma posição estrutural no psiquismo.

Palavras-chave: Supereu, gula estrutural, moralidade, amoralidade

*1 O presente artigo foi baseado na pesquisa de doutoramento de Breno Ferreira Pena, sob orientação da Prof. Dra. Jacqueline de Oliveira e Profa. Dra. Andréa Máris Campos Guerra como co-orientadora. A pesquisa foi subvencionada pela CAPES e teve como título "O supereu estrutural e seus efeitos históricos: das dívidas morais na modernidade, às dívidas de performance no contemporâneo". A tese foi defendida em 1/7/2016, na Pontifícia Universidade Católica de Minas Gerais, no Programa de Pós-graduação em Psicologia.

*2 Universidade Federal do Pará - UFPA (Belém, PA, Brasil).

*33 Pontifícia Universidade Católica de Minas Gerais - PUC-Minas (Belo Horizonte, MG, Brasil).

${ }^{* 4}$ Universidade Federal de Minas Gerais - UFMG (Belo Horizonte, MG, Brasil). 


\section{Introdução}

O presente texto tem como objetivo acompanhar as movimentações freudianas na construção e complexificação do conceito de supereu. Freud, na sua posição de criador, não poderia ser um fiel historiador de seus conceitos, mas o leitor pode seguir o fluxo do texto na trilha do desvelamento da produção conceitual. Em um primeiro momento, buscou-se refazer os caminhos freudianos da construção do conceito de supereu e, em seguida, localizar os deslocamentos e problematizações lacanianas sobre o tema. Assim, nossa proposta pode ser pensada como uma forma de elaboração da história do conceito no interior da teoria, com o objetivo de delinear as especificidades do supereu ao ressaltar sua gula insaciável de gozo como o que o caracteriza e lhe dá uma função absolutamente estrutural na constituição psíquica de todo ser falante.

Freud formula a ideia de supereu no texto de 1923, "O ego e o id”, como uma instância de dupla origem, concepção da qual não abre mão em toda a sua obra. Para Freud, o supereu é representante do isso, seu lado pulsional, mas também herdeiro do complexo de Édipo, sua vertente que está entrelaçada ao ideal do eu.

$\mathrm{Na}$ concepção freudiana, o supereu, por assumir a função dos pais de vigiar, julgar e punir, é considerado herdeiro do complexo de Édipo. Trata-se de uma instância moral e, por vezes, hipermoral, devido à intransigência e à crueldade de suas exigências. Freud deu um lado ao supereu que se articula ao ideal do eu pela moralidade, mas também não deixou de destacar a outra faceta dessa instância - ser representante do isso —, o que justifica a severidade dos imperativos superegoicos, à medida que são fomentados pela própria pulsão de morte. 


\section{ARTIGOS}

No ensino lacaniano, no entanto, o supereu jamais será considerado herdeiro do complexo de Édipo, como lembra Miller (1997a). Essa instância em Lacan é concebida de forma a não deixar dúvidas sobre seu funcionamento, ao ter sua função definida com uma única palavra: Goze!

Segundo Pena (2011),

Lacan desvincula o supereu da proposta freudiana de herdeiro do complexo de Édipo, situando-o não mais como moral, o que propunha Freud, mas como amoral, um agente da pulsão de morte que impõe somente uma ordem: goze! Assim, para o supereu tanto faz se o sujeito goza obedecendo à lei ou transgredindo-a. E, além disso, trata-se de um imperativo de gozo que jamais será cumprido, porque sempre, pela lógica superegoica, é possível exigir um pouco mais de empenho ao sujeito, goze o que ele gozar. Temos, portanto, uma gula pulsional insaciável e amoral como marca registrada do supereu em Lacan. (p. 19)

Para a psicanálise, trabalhar com o supereu, demarcar sua gula estrutural e seu funcionamento, é de suma importância tanto teórica quanto clínica, visto que essa instância gerencia a pulsão de morte e seus efeitos nefastos sobre o desejo e sobre a própria vida. Avesso à Lei e à linguagem, o supereu retorna sobre o sujeito com uma sede insaciável e mortífera de gozo: "Freud e Lacan formularam o supereu como resíduo aniquilador do desdobramento do sujeito contra si mesmo" (Gerez-Ambertín, 2003, p. 225).

\section{Supereu em Freud: A dupla origem}

Apesar de formalizar uma teoria sobre o supereu apenas em 1923, desde o início de suas pesquisas, como demonstra Gerez-Ambertín (2003), Freud já havia desenvolvido várias questões teóricas e clínicas que serviram como subsídio para essa formalização. Diante desse contexto, dois momentos se destacam. O estabelecimento do que Freud nomeou como o ideal do eu, no texto "Narcisismo: uma introdução", de 1914, e a descoberta da pulsão de morte, em "Além do princípio do prazer", de 1920.

O ideal do eu é uma instância psíquica que se forma, por meio da dissolução do complexo de Édipo, quando a criança aceita a interdição do pai e assume as insígnias paternas como ideal. Assim, Freud (1914/1996a), ao conceber o ideal do eu, ressalta que seu surgimento no psiquismo está diretamente relacionado ao estabelecimento do recalque. Diferentemente 
de seu par, o eu ideal, no qual a criança pode se tornar a "majestade o bebê" simplesmente ao corresponder ao olhar apaixonado dos pais. No ideal do eu, é preciso que esse mesmo sujeito se esforce efetivamente para realizar tal ideal - imposto pela cultura, transmitido pelo pai e que exige renúncia pulsional - para que somente ao cumpri-lo possa ser recompensado ao sentir-se amado e reconhecido socialmente.

Freud frisa, ainda nesse texto, que a função de avaliar e julgar esse cumprimento do Ideal seria tarefa de um agente psíquico especial, que se formaria por meio do ideal do eu, quando este for estabelecido no sujeito. Assim, parece que Freud dá características que diferenciam o ideal do eu desse agente psíquico especial que julga. A princípio, alguém pode supor que esse agente já seria até mesmo a antecipação do supereu, diferente do ideal do eu. Todavia, o próprio Freud (1914/1996a) acrescenta uma nota de rodapé para indicar que o supereu seria a futura combinação desse agente especial com o ideal do eu. Fica, assim, mais uma vez implícito que, em Freud, o supereu se articulará com o ideal do eu para sustentar a ideia de uma dupla origem para a instância superegoica: representante do isso e herdeiro do complexo de Édipo. Tal aproximação do supereu e do ideal do eu, todavia, 40 deu início a uma dificuldade que nunca será totalmente resolvida em Freud: a clara diferenciação entre a função do ideal do eu e a do supereu.

A sistematização do ideal do eu e a inferência de um agente especial para avaliar o eu vão criando para Freud um arcabouço teórico que lhe será muito útil no delineamento do que viria a ser sua formulação do supereu: "Exceto o tropeço de designar com um mesmo nome duas comarcas, o horizonte do supereu recebe, em 'Sobre o narcisismo...', um excelente traçado" (Gerez-Ambertím, 2003, p. 58). Assim, mesmo antes de formalizar o conceito de supereu, Freud (1914/1996a) dá início à sua caracterização e afirma que um poder dessa espécie, que avalia, julga e critica, está presente em todos nós. E alerta para a ideia de que, quando assume uma forma patológica, exacerbada, explicaria os delírios, comuns ao paranoico, de ser notado e vigiado. Com o texto sobre o narcisismo, uma divisão do sujeito contra si próprio toma contornos mais definidos. Todavia, somente em 1920, com a formulação da pulsão de morte, Freud dará o passo definitivo para pensar a vertente do supereu como representante do isso, e, em seguida, em 1923, proporá, então, a formulação do supereu.

Após a escrita de "Além do princípio do prazer", de 1920, a psicanálise como um todo, teoria e clínica, sofreria uma torção e nunca mais seria a mesma. Com a teorização da pulsão de morte, Freud constata de forma 


\section{ARTIGOS}

marcante uma divisão do sujeito contra si mesmo, agora para ele uma divisão incontestável. Cria, assim, a partir desse texto, substrato para apontar algo mais primitivo e independente do que o princípio do prazer, e exemplifica-o, por meio da descrição de sonhos traumáticos e da brincadeira do fort-da. Com isso, sugere que o ser humano repetiria, constantemente, situações nas quais não encontra o prazer, mas uma satisfação pulsional no sofrimento. A pulsão de morte, portanto, é caracterizada como a força pulsional que procura o fim, a destruição de todas as tensões existentes no organismo, por meio da compulsão à repetição, definida por Freud como "uma força demoníaca":

As manifestações de uma compulsão à repetição (que descrevemos como ocorrendo nas primeiras atividades da vida mental infantil, bem como entre os eventos do tratamento psicanalítico) apresentam em alto grau um caráter instintual e, quando atuam em oposição ao princípio do prazer, dão aparência de alguma força demoníaca em ação. (Freud, 1920/1996b, p. 46)

A pulsão de morte constitui, dessa forma, sem sombra de dúvidas, um ponto fundamental para que Freud, três anos depois, pudesse entender e explicar a severidade excessiva do supereu contra o sujeito: "o supereu representa a continuidade e o amadurecimento de uma elaboração que, ao nosso ver, fora apenas esboçada com a postulação da pulsão de morte" (Rudge, 2006, p. 54). A pulsão de morte marca uma busca pela própria aniquilação do sujeito, por meio da compulsão à repetição, diametralmente oposta à lógica do desejo inconsciente. Como argumenta Cardoso (2002, p. 13), a noção de supereu está ligada à pulsão de morte.

Assim, com a teorização da pulsão de morte surgem de forma bem fundamentada os princípios teóricos para Freud formular a vertente pulsional e mortífera do supereu, como representante do isso. Elaborada a ideia de instância do ideal do eu, base da vertente do supereu herdeiro do complexo de Édipo, com a pulsão de morte, o arcabouço teórico para definição do supereu freudiano encontra-se, finalmente, consolidado.

O conceito de supereu, então, foi formalizado por Freud em 1923, em sua segunda tópica, na qual também há teorizações sobre outras duas instâncias: o eu e o isso. Essas duas instâncias, no entanto, já haviam sido trabalhadas anteriormente por Freud e nesse texto de 1923 são retomadas. É interessante notar, como frisa Miller (1986), que, apesar de o supereu ser a grande novidade desse texto, é a única instância que não é mencionada no título. Entretanto, mesmo formulando um pensamento sobre essa instância 
psíquica, nunca foi tarefa fácil para Freud caracterizá-la definitivamente, talvez pelo fato de, em sua leitura, o supereu ter uma dupla vertente que precisa ser levada em conta para sistematizar seu funcionamento. Essa conclusão vai marcar a posição freudiana frente ao supereu, dando um caráter paradoxal a ele em sua obra: "O supereu é herdeiro do isso, mas também é herdeiro do complexo de Édipo. Conclusão paradoxal, cabeça de uma longa série que percorre de ponta a ponta a obra freudiana" (Gerez-Ambertín, 2003, p. 105).

Freud (1923/1996c) afirma que o supereu tem suas raízes no isso, por meio de uma identificação da criança com o seu pai da pré-história. Caracteriza essa identificação como imediata, portanto, direta e não mediada, dando-se antes mesmo de qualquer investimento de objeto. Observa, ainda, que o supereu, a partir de então, posicionar-se-ia como uma instância especial do eu, que dele se manteria à parte para dominá-lo severamente. Esse domínio, ressalta Freud, é favorecido pelo fato de a identificação se dar primitivamente, no momento em que o eu ainda é bastante frágil.

Quando a criança, ao final do complexo de Édipo, percebe seu pai como ideal e não mais como rival, isso faz com que as tendências libidinais, até então pertencentes ao complexo de Édipo, sejam amplamente dessexualizadas, e os componentes agressivos fiquem a serviço do supereu. Isso demonstraria, segundo Freud, a grande severidade do supereu e suas íntimas interações com a pulsão de morte. $\mathrm{O}$ fato de a criança ter o pai como modelo, todavia, também remete Freud à vertente do supereu herdeiro do complexo de Édipo. Com a dissolução do complexo de Édipo, o supereu funcionaria como uma espécie de representante da autoridade paterna, na medida em que são os pais que introduzem a criança em seu sistema de costumes e valores, apontando o que é certo ou errado, vigiando, julgando e punindo a criança, quando necessário, em nome da "boa educação":

Embora ele seja acessível a todas as influências posteriores, preserva, não obstante, através de toda a vida, o caráter que lhe foi dado por sua derivação do complexo paterno - a saber, a capacidade de manter-se à parte do ego e dominá-lo. Ele constitui uma lembrança da antiga fraqueza e dependência do ego, e o ego maduro permanece sujeito à sua dominação. Tal como a criança esteve um dia sob a compulsão de obedecer os pais, assim o ego se submente ao imperativo categórico do seu superego. (Freud, 1923/1996c, p. 61)

Quando assume esse lugar, todavia, o supereu pode ser, e de fato o é, ainda mais cruel e implacável que os próprios pais ao cobrar os ideais estabelecidos — ideais sempre inalcançáveis. Além disso, não há como 


\section{ARTIGOS}

se esconder nada; nem um ato, nem mesmo uma intenção. Nada passa desapercebido ao julgamento do supereu. Ora, esse fato, por si só, já demonstra um caráter muito diferente do controle do supereu em relação ao dos pais. Mas as diferenças vão além, pois o supereu pode conhecer até mesmo o que é desconhecido para o sujeito: "Então Freud daí conclui que o supereu é onisciente, o supereu sabe tudo - sabe até o que o sujeito não sabe, ou seja, as pulsões que se abrigam no recalque" (Soler, 2012a, p. 127).

Um ano após a publicação de "O ego e o id", Freud escreve outro texto e, ao teorizar sobre um masoquismo primário, traça de forma cada vez mais consistente uma posição estrutural para essa instância, recém-descrita por ele: "Com o delineamento do masoquismo primário ou erógeno, o campo minado do supereu alcança, em 'Problema econômico do masoquismo', uma posição claramente estruturante na subjetividade" (Gerez-Ambertín, 2003, p. 123). Para descrever o masoquismo, Freud propõe três formas: o masoquismo erógeno, o feminino e o moral. Ele esclarece que essa divisão não se faz para criar categorias distintas, já que o masoquismo erógeno ou primário está na base dos outros dois que também se relacionam entre si. A proposta freudiana aponta para um nó masoquista presente em todo neurótico.

O masoquismo erógeno, constitutivo e originário, faz um ponto de ancoragem com a pulsão sexual; o masoquismo feminino é exemplificado por Freud com a fantasia de homens que se excitam com a ideia de serem amarrados, humilhados, obrigados a obedecer à pessoa amada; já o moral tem vínculo mais frouxo com a sexualidade e se traduz por uma necessidade de punição, que pode relacionar-se a qualquer um ou até mesmo ao próprio destino, que "se torna" punitivo. Essas formas de comportamento masoquista, em alguma medida presentes em todo sujeito em função da própria pulsão de morte, entrelaçam-se na instância psíquica favorecendo traços masoquistas no eu, que se articulam com o supereu sádico e se expressam como necessidade inconsciente de punição. Essa dinâmica pulsional severa diz da vertente do supereu freudiano, representante do isso, que alimenta a outra vertente superegoica, herdeira do Édipo, tornando-a também dura e inflexível contra o sujeito: "O superego - a consciência em ação no ego — pode então tornar-se dura, cruel e inexorável contra o ego que está a seu cargo. O imperativo categórico de Kant é, assim, o herdeiro direto do complexo de Édipo" (Freud, 1924/1996d, p. 185).

Freud (1933[1932]/1996e) continua seu trabalho teórico e clínico que parece levar cada vez mais a supor um supereu de cunho estrutural e, em sua "Conferência XXXI", dez anos depois de formular seu conceito, retoma-o e 
passa a discutir o que chama de "metamorfose do relacionamento parental em superego" (Freud, 1933[1932]/1996e, p. 68). Com isso, põe-se a questionar a dialética das identificações na formação do supereu: "eu mesmo não estou, de modo algum, satisfeito com estes comentários sobre a identificação" (p. 69). Afirma que o supereu, ao assumir a função paterna de autoridade, faz uma escolha unilateral, ao tomar apenas o rigor e a severidade dos pais, enquanto tudo indica que o carinho e a ternura não são assimilados. Além disso, mesmo as crianças criadas sem rigor por seus pais poderiam, ainda assim, ter um supereu severo, concluindo, dessa forma, que o supereu não se formaria de acordo com a educação dada à criança, mas de acordo com o supereu dos seus próprios pais:

Assim, o superego de uma criança é, com efeito, construído segundo o modelo não de seus pais, mas do superego de seus pais; os conteúdos que ele encerra são os mesmos, e tornam-se veículo da tradição e de todos os duradouros julgamentos de valores que dessa forma se transmitiram de geração em geração. (p. 72)

A instância moral representa a identificação com as figuras de outro, mas também é a internalização residual dos investimentos objetais abandonados. O supereu tem íntima relação com o isso, pois conhece de perto suas escolhas objetais proibidas. Por outro lado, tem uma estreita relação com a moralidade, pois "representa uma formação reativa energética contra essas escolhas" (Freud, 1923/1996c, p. 47).

Freud, porém, nunca irá abandonar a sua hipótese de uma dupla origem para a instância superegoica (Cardoso, 2002), afirmando nessa mesma Conferência: "Como veem, o superego se funde com o id; na verdade, como herdeiro do complexo de Édipo, tem íntimas relações com o id; está mais distante do sistema perceptual do que o ego" (Freud, 1933[1932]/1996e, p. 83).

Freud estabelece, assim, aspectos fundamentais para o entendimento do funcionamento do supereu, mas, apesar de todo o seu esforço e brilhantismo, deixa fronteiras abertas, pelas quais Lacan procura avançar.

\section{O supereu em Lacan: Goze! E mais um pouco... e mais...}

A perspectiva lacaniana sobre o supereu atribui a essa instância uma gula insaciável e estrutural. Lacan em nenhum momento de seu ensino coloca, como Freud o fez, o supereu como herdeiro do complexo de Édipo 


\section{ARTIGOS}

(Freitas \& Rudge, 2011), podendo, com isso, separar objetivamente o supereu e o ideal do eu. Essas duas instâncias podem se articular e muitas vezes até mesmo se retroalimentar, mas têm funcionamento próprio. Para Lacan, desde seu primeiro seminário, o supereu pune, castiga e constrange, enquanto o ideal do eu tem outro estatuto e pode levar o sujeito a momentos de euforia e exaltação: "O supereu é constrangedor e o ideal do eu exaltante" (Lacan, 1953-54/1986, p. 123).

O ideal do eu, portanto, pode ter uma função de realização em si mesmo, algo totalmente impensável para se caracterizar o supereu lacaniano, que é invariavelmente terrível e cruel com o sujeito. Sempre cobra imperativamente um algo a mais de gozo, que se traduz em exigências descabidas e intermináveis - gozar é sua máxima e única finalidade. Por sua vez, o ideal do eu, por estar completamente ligado ao campo simbólico, tem outra perspectiva: "O núcleo do ideal do eu é o significante, enquanto o julgamento do supereu é o objeto $a$ " (Miller, 1997b, p. 385).

Isso, todavia, não quer dizer que o ideal do eu não possa ser incômodo, e até mesmo de certa forma terrível, quando se torna um ideal muito maior do que aquilo a que o sujeito pode corresponder. O ideal do eu, em si, como o próprio nome diz, é algo distante, ideal, certamente inalcançável, servindo muito mais como norte. Entretanto, dependendo de cada sujeito, pode vir a causar dor; oscilar da exaltação à opressão. Esse definitivamente não é o caso do supereu, que atua num campo que está além desse princípio.

O ideal do eu também pode ser esmagador: ele pode oprimir dando ao sujeito o sentimento da imensa distância que há entre o que ele queria ser, isto é, seus ideais, e o que ele percebe, apesar de tudo (quando tem um pouco de bom senso), como o que ele é (Soler, 2012a, p. 120).

De toda forma, a afirmação de Soler, como ela própria esclarece, também não pretende de maneira alguma igualar o ideal do eu ao supereu, pois a formulação desses conceitos no ensino lacaniano não deixa dúvidas sobre a enorme diferença entre eles. Ao trazer as insígnias paternas calcadas em virtudes simbólicas socialmente reconhecidas, o ideal do eu, mesmo sendo um parâmetro muitas vezes inalcançável, pode alimentar a autoestima: "O sujeito pode ser esmagado por seus ideais, sentir-se desigual a eles, mas thes permanece fiel, e isso alimenta a sua autoestima" (Soler, 2012a, p. 120). Já o supereu apresenta-se não por meio de virtudes, mas, ao contrário, das falhas do pai com as quais o sujeito se vê completamente condenado a lidar e a reproduzir em sua vida: "É o discurso do meu pai, por exemplo, na medida em que meu pai cometeu faltas as quais estou absolutamente condenado a reproduzir — é o que se denomina superego" (Lacan, 1954-55/1985a, p. 118). 
Gerez-Ambertín (2009), em texto sobre o Holocausto, também retoma a questão da diferenciação entre o supereu e o ideal do eu e diz que o ideal do eu, ao oscilar entre a exaltação e a opressão, diferencia-se do supereu, que, como visto, sempre submete ao castigo e constrange. Ressalta, no entanto, que na prática a separação entre essas instâncias é bastante sutil. A autora propõe pensar, então, em que momento poderia dar-se a transição de uma instância a outra, da exaltação/opressão do ideal do eu, ao submeter-se à dimensão mortífera do supereu, que se encontra regida pelo além do princípio do prazer.

Essa estranha afinidade do "Ideal do eu" com o supereu indica um caminho importante de pesquisa na teoria, na clínica e no mal-estar na cultura. A encarnação do Ideal sempre oscila entre a exaltação e a opressão. Apesar da primazia simbólico-imaginária do Ideal, que promove o lado amável das insígnias, a captura da imagem não deixa de coagir: Deves ser assim para te tornares amável!, mandato que, paradoxalmente, acaba por oprimir/dividir o sujeito contra si mesmo e mostra a passagem de uma primazia simbólicoimaginária para o real do gozo. (Gerez-Ambertín, 2009, p. 250)

Nesse momento, em que o gozo passa a envolver e dominar o ideal, entra-se na seara do supereu, pois, como afirma Lacan (1972-73/1985b) no final de seu ensino, no qual há uma prevalência do real, para ele não há dúvidas ao definir o supereu: é apenas essa instância que pode ordenar o gozo ao sujeito. De toda forma, cabe frisar que Lacan já pensava o supereu como algo pulsional, primitivo e implacável, desde o início da constituição do sujeito, mesmo em seus primeiros seminários.

A perspectiva de um supereu primitivo e nefasto, inclusive, possibilitou a Lacan trabalhar, já em $O$ seminário, livro 3, a presença do supereu em casos de psicose. Contudo, apenas alguns anos mais tarde, com o amadurecimento teórico e clínico, no Seminário, livro 10, é que Lacan, perto de inaugurar seu segundo ensino, pôde formular o supereu como objeto $a$, cujo aparecimento se daria, enquanto supereu, na sua forma "voz" (Cordeiro \& Bastos, 2011). Essa formalização consolida teoricamente e de forma contundente a concepção lacaniana de uma instância intrusiva, extremamente real e primitiva.

O supereu, portanto, é incorporado pelo sujeito logo no início de sua constituição. O objeto $a$ enquanto voz é completamente primitivo; surge imposto pela intromissão do Outro primordial. Como expõe Soler (2012b), é importante destacar que o objeto $a$ em um primeiro momento da constituição psíquica não pode ser entendido como o objeto causa de desejo, apesar de estar estruturalmente ligado a essa função. O objeto $a$ surge a princípio 


\section{ARTIGOS}

como resto - fruto do encontro de um sujeito ainda inexistente com o Outro originário - e é esse objeto que o sujeito vai incorporar como supereu.

O objeto $a$, em $O$ seminário, livro 10 , foi formalizado por meio de cinco formas: objeto oral, objeto anal, objeto fálico, objeto olhar e objeto voz. Dentre eles, Lacan faz questão de ressaltar que olhar e voz estão em outro patamar. Esse dois objetos rompem o campo significante e se apresentam em uma dimensão Real: "Se ele pôde, nesse seminário, acrescentar o olhar e a voz, é porque arrancou o estatuto de objeto do significante" (Miller, 2005, p. 29).

O objeto voz como supereu é literalmente incorporado pelo sujeito por ser algo que não pode ser assimilado por ele. Um objeto impensável, eco do real, diz Lacan (1962-63/2005), por ser uma voz sem atributos, que não é modulada, apenas vocalizada, sem qualquer fonematização. Nesse contexto, é do Outro primordial que se recebe esta voz, "um tu és sem atributo". Todavia, é impossível instituir o "eu" sem este "tu és" do supereu.

Para Lacan, não é possível instituir o $J e$ sem o tu do supereu. Tu que se precipita sobre o sujeito infantil, corpo estranho, invasor e intimidatório, "tu que tomba" e toma posse da intimidade — como patrão da estância subjetiva. Transfiguração total em que um externo se faz íntimo. Extimidade: "algo que está incluído em seu núcleo". Extimidade que é a Coisa excluída em seu interior: supereu real. (Gerez-Ambertín, 2003, p. 227; grifos do autor)

Nesse sentido, Lacan (1962-63/2005) sugere como metáfora — da incorporação primitiva do supereu, enquanto objeto $a$, voz - a incorporação dos grãos de areia que a dáfnia precisa realizar para sobreviver. A dáfnia é um crustáceo conhecido por pulga-d'água, que tem na areia um guizo fundamental para seu equilíbrio. Da mesma forma aconteceria com a criança ao incorporar uma voz que, sem ser assimilada, funcionaria como suporte para a função de vazio, que é o vazio do Outro como tal, como objeto voz para o sujeito.

De que objeto se trata? Daquilo que chamamos voz.

Nós o conhecemos bem, acreditamos conhecê-lo bem, a pretexto de conhecermos seus dejetos, as folhas mortas, sob a forma das vozes perdidas da psicose, e seu caráter parasitário, sob a forma dos imperativos interrompidos do supereu. (Lacan, 1962-63/2005, p. 275)

Outro momento a se destacar, no ensino lacaniano, nessa perspectiva de um supereu Real e intratável é $O$ seminário, livro 18, no qual Lacan, dando continuidade a seu ensino, faz um pronunciamento a princípio extremamente enigmático, mas que pode frisar o vínculo eterno e mortífero do supereu com 
o gozo, além de proporcionar uma valiosa indicação clínica: "A única coisa de que nunca tratei é do supereu" (Lacan, 1971/2009, p. 84). Para Campos (2002), apesar do enigma que envolve a frase, Lacan aponta aí para o intratável do supereu, pois dessa instância não se trata jamais. Portanto, com o supereu não há negociação: sua gula é estrutural, insaciável. O tratamento, assim, não pode ser negociação com o supereu com qual o sujeito sempre irá perder; com ele não há como negociar. Assim, o tratamento clínico visa à nomeação do gozo em questão, favorecendo certa transposição desse gozo, um saber fazer com ele, para permitir a decisão do sujeito de bancar seu desejo. Trata-se de um saber fazer com o gozo que incide diretamente sobre a ressonância dos imperativos de gozo do supereu sobre o sujeito. Tais imperativos perdem força e sentido frente a uma posição subjetiva, que favorece o objeto $a$, enquanto causa de desejo.

Lacan, ainda nesse seminário, afirma que a grande invenção da segunda tópica freudiana foi o supereu, e se pergunta sobre qual seria a sua essência. Qual a ordem, qual a imposição do supereu? Responde que sua ordem se dá por meio do pai original, como apelo ao puro gozo, da não castração, ordem impossível de se cumprir: "O supereu tem um tipo de economia que pode ser 48 classificada como economia do agiota, pois ele exige mais sacrifícios de quem lhe é devedor" (Campos, 2015, p. 187). As ordens do supereu são totalmente inexequíveis, sendo sua gula como objeto $a$ estrutural e insaciável; à medida que o sujeito tenta cumprir seus mandados, eles sempre são colocados um passo à frente, exigindo um esforço maior. Há, portanto, um impossível de se cumprir; goze o que gozar o sujeito, ele estará sempre em dívida e culpa com o supereu.

Dois anos mais tarde, Lacan ministra seu seminário extremamente significativo para se compreender o supereu em seu ensino, pois é nele que define seu campo de ação como a única instância no psiquismo capaz de obrigar o sujeito a gozar. Trata-se de O seminário, livro 20, em que Lacan retoma a questão do supereu gozador e questiona o que se define por gozo, chegando à proposição da hipótese de que se trata de uma instância negativa, que não serviria para nada. Miller (2000) esclarece que esse seminário traz uma nova concepção para a compreensão do gozo, o paradigma do gozo da não relação. O gozo se estabelece aqui, portanto, como fato e como Uno, não fazendo ligação com o Outro: "o gozo Uno pertence ao real, enquanto o gozo do Outro já aparece como uma construção problemática” (p. 104). E é por meio dessa nova perspectiva para o gozo, mas, sobretudo, por anos de trabalho teórico/clínico, que Lacan pôde finalmente afirmar: "Nada força 


\section{ARTIGOS}

ninguém a gozar, senão o supereu. O supereu é o imperativo de gozo Goza!" (Lacan, 1972-73/1985b, p. 11).

Lacan, ainda nesse seminário, volta a falar do supereu e indica sua correlação com a castração; entretanto, como argumenta Gerez-Ambertín, "a proposição do supereu como correlato da castração alude para esse avesso da metáfora. A antinomia se dá entre Desejo-Lei e Gozo. O supereu, coordenado ao gozo e não ao desejo, é uma chamado à não castração" (Gerez-Ambertín, 2003, p. 224).

Assim, o supereu, correlato da castração, se utiliza das faltas, das falhas do pai, do ideal estabelecido em cada um, como uma espécie de ferramenta que se forma da própria relação do sujeito com a Lei, com o desejo e com o gozo. O supereu se favorece do romance familiar, dos modos de gozo que capturam o sujeito, da cultura em que ele se insere, de seus objetos de gozo, para voltar-se como imperativo de gozo contra esse mesmo sujeito. Exige dele sempre um esforço a mais de gozo seja lá quem for ou qual seja seu romance familiar, sua cultura, os modos de gozo em questão: nada importa para o supereu, senão gozar. Esse é o supereu lacaniano com sua gula estrutural que quer e exige gozar, não importando absolutamente como. O supereu tal qual propõe Lacan, portanto, carrega inexoravelmente uma gula estrutural, que se pode resumir em uma única palavra, mas de permanente ressonância sobre o sujeito: Goze!

Exemplificando de forma geral e esquemática: se alguém goza obedecendo à lei em suas minúcias, o supereu vai exigir cada vez mais sacrifício e retidão desse sujeito para alcançar punição a cada momento em que ele não chegar às metas. Se, por outro lado, o sujeito gozar por meio da transgressão da lei, o supereu vai exigir cada vez mais e mais o gozo de infringir, de transgredir a lei, em uma compulsão que nunca se sacia. Outros exemplos são a compulsão por compras ou mesmo a toxicomania, sintomas atuais, nos quais a partir do momento em que o mais-de-gozar assume lugar privilegiado para o sujeito, torna-se ferramenta do supereu, que denuncia insistentemente o fato de que o gozo obtido com esses objetos é sempre insuficiente; e exige mais. Em todo caso, é essencial frisar, não se trata de uma escolha do sujeito em cumprir tais exigências, estando a questão muito mais ligada a uma impossibilidade de recusá-las: "O fato de o sujeito dizer 'sim' e ser obediente à injunção do supereu não caracteriza uma aquiescência consentida, e, sim, fruto de uma impossibilidade de dizer "não"' (Campos, 2015, p. 197).

O supereu é completamente insaciável, mas suas ordens de gozo se encarnam em cada sujeito de forma singular e até mesmo histórica, dependendo da época e dos valores sociais sob os quais se vive. Como lembra Lacan (1948/1998): “a opressão insensata do supereu está na raiz 
dos imperativos motivados da consciência moral" (p. 119). Além disso, se pensarmos que a castração, no segundo ensino de Lacan, remete à castração já inerente à própria linguagem, ela se daria em todos os seres de linguagem. Assim, independentemente de se passar pelo Édipo, o supereu seria também o correlato da castração estrutural própria da linguagem, que não dá conta de recobrir o Real.

É com a castração estrutural, com a castração da própria linguagem, que o supereu gozador já se coloca como um imperativo de gozo que escapa à simbolização desde o início da vida do ser humano. O supereu se volta contra o ser de linguagem a partir de sua estrutura, exigindo sempre um pouco a mais de gozo, seja lá qual for a estrutura em questão: "é fundamental encontrar o lugar que cabe ao supereu na estrutura do sujeito e, a partir daí, confrontar os recursos dessa mesma subjetividade para negociar com esta instância feroz" (Gerez-Ambertín, 2003, p. 226).

Posteriormente, no texto "Televisão", Lacan, mais uma vez, retomaria a questão do supereu como uma instância feroz, não domesticada pela linguagem, mas que surge da própria falha da linguagem que não recobre tudo. Isso reforça uma posição ainda mais estrutural para o supereu em seu 50 ensino. Ele chama atenção, contudo, para a contribuição de Freud que também trabalha o lado feroz do supereu: "A gulodice pela qual Freud denotou o supereu é estrutural - não é um efeito da civilização, mas um mal-estar (sintoma) na civilização" (Lacan, 1973/2003, p. 528). A estrutura que funda a linguagem já traz a marca da castração Real pela presença do supereu, objeto $a$, enquanto resto que resiste à entrada na linguagem e se apresenta enquanto voz. É, portanto, algo que se dá no início da vida do ser humano, por meio da presença incômoda da voz do Outro primordial.

O supereu, para Lacan, corresponde a uma instância feroz que exige inexoravelmente o gozo. Assim, Miller (1986) propõe ser possível analisar de forma didática o supereu no ensino lacaniano por meio dos três registros: o Imaginário, em suas figuras obscenas; e o Simbólico, através de suas leis insensatas. Mas é no registro Real, diz ele, que se destaca sua gula estrutural, seu funcionamento enquanto objeto $a$, imperativo de gozo inexequível e insaciável.

Além disso, é por meio do registro do Real, das formalizações sobre o gozo, que se entende melhor o supereu, seu modo de funcionamento e sua potência de destruição — suas exigências descabidas para o sujeito, por sua sede absolutamente interminável de gozo, goze o que se gozar.

Por fim e com referência à consolidação de uma teoria lacaniana sobre o supereu, acreditamos que essa teoria ainda estava em construção quando 


\section{ARTIGOS}

da morte de Lacan. Entretanto, é justo reconhecer nela uma delimitação conceitual extremamente indicativa: o supereu se refere ao gozo e, como imperativo, de gozo é. Desta demarcação fundamental inauguram-se múltiplas possibilidades de indagação que têm o objeto $a$ como orientatio, ainda que não estejam resolvidos todos os mistérios da formulação lacaniana do supereu na teoria e na clínica (Gerez-Ambertín, 2003, p. 219; grifos do autor).

\section{Considerações finais}

No ensino lacaniano, o supereu tem como função e é o único responsável por ordenar o gozo ao sujeito. Em Freud, por seu turno, também se pode afirmar que, mesmo que ele conceda ao supereu um lado herdeiro do complexo de Édipo - ao assumir a autoridade paterna de vigiar, julgar e punir - , como o supereu também é representante do isso, seus imperativos contra o sujeito são insaciáveis e inevitavelmente acabam caindo no excesso pulsional. Nas formulações de Freud, em nenhum momento o supereu é considerado benevolente, nem mesmo razoável, em suas exigências pulsionais. Pode-se afirmar que, guardadas as diferenças de formulação conceitual, tanto para Freud quanto para Lacan, o supereu se caracteriza por sua gula de gozo, feroz e estrutural.

A principal diferença entre os dois autores — parece plausível pensá-la a partir dos desdobramentos históricos internos à formulação teórica de cada um - não se encontra em um supereu que proíbe o gozo e um que o incita, mas na nítida diferenciação entre ideal do eu e supereu proposta por Lacan. Isso criou condições para se pensar o supereu primitivo plenamente constituído e em funcionamento desde o início da vida do ser humano e em qualquer estrutura. Além disso, trouxe a possibilidade de concebê-lo, enquanto objeto $a$, imperativo de puro gozo, que pode ou não se utilizar do ideal do eu de cada sujeito como uma ferramenta a mais para atormentá-lo.

A partir da realização do percurso histórico do conceito nas duas obras, podemos dizer que o supereu se refere, portanto, a uma instância que se mostra fundamental para entender um modo de funcionamento destrutivo que habita todo ser falante e se revela de forma silenciosa, mas impiedosa, ao exigir o gozo a qualquer custo. O supereu obriga todos os sujeitos a gozar. Sua gula de gozo inesgotável e impiedosa é estrutural, na medida em que faz parte da constituição do próprio ser humano. É intransigente, querendo apenas gozar, não importando como, não escolhendo quando. Não traz, ainda, 
nenhuma preocupação verdadeira com o porquê de se gozar. Para alimentar sua gula insaciável, então, o supereu engendra truques que se impõem, de maneira singular, mas sempre com um único e mesmo objetivo: GOZE!

\section{Referências}

Campos, S. P. R. (2002). As vertentes conceituais do supereu na clínica da neurose obsessiva. (Dissertação de Mestrado). Universidade Federal de Minas Gerais, Belo Horizonte, Brasil.

Campos, S. P. R. (2015). Supereu/Uerepus: das origens aos seus destinos. Belo Horizonte, MG: Escola Brasileira de Psicanálise.

Cardoso, M. R. (2002). Superego. São Paulo, SP: Escuta.

Cordeiro, N. M. L., \& Bastos, A. (2011). O supereu: imperativo de gozo e voz. Tempo psicanalítico, 43(2), 439-457. Recuperado em 20 jan. 2019 de: <http://pepsic. bvsalud.org/scielo.php?script=sci_arttext\&pid=S0101-48382011000200011\&ln $\mathrm{g}=\mathrm{pt} \& \mathrm{nrm}=$ iso $>$.

Freitas, A. L., \& Rudge, A. M. (2011). O supereu entre o amor e o gozo. Tempo psicanalítico, 43(2), 244-267. Recuperado em 20 jan. 2019 de: $<$ http://pepsic. bvsalud.org/scielo.php?script=sci_arttext\&pid=S0101-48382011000200001\&ln $\mathrm{g}=\mathrm{pt \& nrm}=$ iso $>$.

Freud, S. (1996a). Sobre o narcisismo: uma introdução. In Edição Standard Brasileira das Obras Psicológicas Completas de Sigmund Freud (Vol. XIV, pp. 81-108). Rio de Janeiro, RJ: Imago. (Trabalho original publicado em 1914).

Freud, S. (1996b). Além do princípio de prazer. In Edição Standard Brasileira das Obras Psicológicas Completas de Sigmund Freud (Vol. XVIII, pp. 17-75). Rio de Janeiro, RJ: Imago. (Trabalho original publicado em 1920).

Freud, S. (1996c). O ego e o id. In Edição Standard Brasileira das Obras Psicológicas Completas de Sigmund Freud (Vol. XIX, pp. 27-71). Rio de Janeiro, RJ: Imago. (Trabalho original publicado em 1923).

Freud, S. (1996d). O problema econômico do masoquismo. In Edição Standard Brasileira das Obras Psicológicas Completas de Sigmund Freud (Vol. XIX, pp. 177-188). Rio de Janeiro, RJ: Imago. (Trabalho original publicado em 1924).

Freud, S. (1996e). Conferência XXXI. In Edição Standard Brasileira das Obras Psicológicas Completas de Sigmund Freud (Vol. XXII. pp. 63-84). Rio de Janeiro, RJ: Imago. (Trabalho original publicado em 1933).

Gerez-Ambertín, M. (2003). As vozes do supereu. São Paulo, SP/Caxias do Sul, RS: Cultura/EDUCS. 


\section{ARTIGOS}

Gerez-Ambertín, M. (2009). Entre dívidas e culpas: crítica da razão sacrificial. Rio de Janeiro, RJ: Cia. de Freud.

Lacan, J. (1985a). O seminário. Livro 2. O eu na teoria de Freud e na técnica da psicanálise. Rio de Janeiro, RJ: Jorge Zahar. (Trabalho original publicado em 1954-55).

Lacan, J. (1985b). O seminário. Livro 20. Mais, ainda. Rio de Janeiro, RJ: Jorge Zahar. (Trabalho original publicado em 1972-73).

Lacan, J. (1986). O seminário. Livro 1.Os escritos técnicos de Freud. Rio de Janeiro, RJ: Jorge Zahar. (Trabalho original publicado em 1953-54).

Lacan, J. (1998). A agressividade em psicanálise. In Escritos (pp. 104-126). Rio de Janeiro, RJ: Jorge Zahar. (Trabalho original publicado em 1948).

Lacan, J. (2003). Televisão. In J. Lacan, Outros escritos (pp. 508-543). Rio de Janeiro, RJ: Jorge Zahar. (Trabalho original publicado em 1973).

Lacan, J. (2005). O seminário. Livro 10. A angústia. Rio de Janeiro, RJ: Jorge Zahar. (Trabalho original publicado em 1962-63).

Lacan, J. (2009). O seminário. Livro 18. De um discurso que não fosse semblante. Rio de Janeiro, RJ: Jorge Zahar. (Trabalho original publicado em 1971).

Miller, J.-A. (1997a). Sobre Kant com Sade. In Lacan elucidado (pp. 153-218). Rio de Janeiro, RJ: Jorge Zahar.

Miller, J.-A. (1997b). Patologia da ética. In J.-A. Miller, Lacan elucidado (pp. 329-386). Rio de Janeiro, RJ: Jorge Zahar.

Miller, J.-A. (1986). A clínica do supereu. In Recorrido de Lacan (pp. 131-147). Buenos Aires, Ar: Manantial.

Miller, J.-A. (2000). Os seis paradigmas do gozo. Opção Lacaniana: Revista Brasileira Internacional de Psicanálise, 26/27, 87-105.

Miller, J.-A. (2005). Introdução à leitura do seminário 10 da angústia de Jacques Lacan. Opção Lacaniana: Revista Brasileira Internacional de Psicanálise, 43, 7-91.

Pena, B. F. (2011). O Supereu e suas nuances. Reverso, 33(62), 15-21.

Rudge, A. M. (2006). Pulsão de morte como efeito do supereu. Ágora: estudos em teoria psicanalítica, 9, 47-58.

Soler, C. (2012a). Declinações da angústia: curso 2000-2001. São Paulo, SP: Escuta.

Soler, C. (2012b). Seminário de leitura de texto Ano 2006-2007: Seminário A angústia, de Jaques Lacan. São Paulo, SP: Escuta. 


\section{Resumos} gluttony)

(Superego in Freudian and Lacanian: from morality to amorality, a structural

This article offers a discussion on the superego based on the thoughts of Freud and Lacan and by focusing on the way it functions. We notice that what prevails are its structural gluttony, its status of Reality, and its status of psychic instance which are able to force the subject to seek pleasure. We describe clinical and theoretical vicissitudes of the superego from a historical perspective, from the excess of morality described by Freud to the amorality unveiled by Lacan and conclude that the gluttony of the superego for pleasure is what provides it with a structural position in the psyche.

Key words: Superego, structural gluttony, morality, amorality

(Le surmoi chez Freud et Lacan: de la moralité à l'amoralité, une gloutonnerie structurelle )

Cet article cherche à démarquer une formulation du surmoi en prenant comme base le travail de Freud et l'enseignement de Lacan. Nous soulignons son mode de fonctionnement et plus précisément sa gloutonnerie structurelle, son statut Réel et son statut d'instance psychique capable d'obliger l'individu à jouir. Retracer les vicissitudes théoriques et cliniques du surmoi par un chemin historique qui mène de l'excès de moralité décrit par Freud à l'amoralité dévoilée par Lacan témoigne de sa gourmandise de jouissance qui lui confère une position structurelle dans le psychisme.

Mots clés: Surmoi, gloutennerie structurelle, moralité, amoralité

(El superyó en Freud y Lacan: de la moralidad a la amoralidad, una gula estructural )

En este artículo se buscó demarcar una formulación sobre el superyó, apoyada en la obra de Freud y en las enseñanzas de Lacan, que destacara su forma de funcionamiento, en el cual prevalece su gula estructural, su estatuto real y su estatuto de instancia psíquica capaces de obligar al sujeto a gozar. Trazar las vicisitudes teóricas y clínicas del superyó por un recorrido histórico que lleva del exceso de moralidad descrito por Freud a la amoralidad descubierta por Lacan demuestra su gula de goce como lo que le confiere una postura estructural en el psiquismo.

Palabras clave: Superyó, gula estructural, moralidad, amoralidad 


\section{ARTIGOS}

Citação/Citation: Pena, B. F., Moreira, J. de O., Guerra, A. M. C. (2020, março). O supereu em Freud e Lacan: da moralidade à amoralidade, uma gula estrutural. Revista Latinoamericana de Psicopatologia Fundamental, 23(1), 37-56. http://dx.doi.org/10.1590/ 1415-4714.2020v23n1p33.4.

Editora/Editor: Profa. Dra. Sonia Leite

Submetido/Submitted: 28.5.2019 / 5.28. 2019 Revisado/Revised: 11.12.2019 / 12.11.2019

Aceito/Acepted: $20.1 .2020 / 1.20 .2020$

Copyright: (C) 2009 Associação Universitária de Pesquisa em Psicopatologia Fundamental/ University Association for Research in Fundamental Psychopathology. Este é um artigo de livre acesso, que permite uso irrestrito, distribuição e reprodução em qualquer meio, desde que o autor e a fonte sejam citados / This is an open-access article, which permits unrestricted use, distribution, and reproduction in any medium, provided the original authors and sources are credited.

Financiamento/Funding: Este trabalho recebeu apoio da Coordenação de Aperfeiçoamento de Pessoal de Nível Superior - Capes (Brasília, DF, Br) / This work is supported by. Coordenação de Aperfeiçoamento de Pessoal de Nível Superior - Capes (Brasília, DF, Br).

Conflito de interesses/Conflict of interest: Os autores declaram que não há conflito de interesses. / The authors declare that there is no conflict of interest.

\section{Breno Ferreira Pena}

Psicanalista, Psicólogo, pós-graduado em gestão de pessoas pela Fundação Getúlio Vargas - FGV. Doutor e Mestre em Psicologia pela Pontifícia Universidade Católica de Minas Gerais - PUC-Minas (Belo Horizonte, MG, Br). Professor da Faculdade de Psicologia e do Programa de Pós-Graduação em Psicologia da Universidade Federal do Pará - UFPA (Belém, PA, Br). Professor da Residência Multiprofissional, Complexo Hospitalar UFPAEBSERH, Unidade João de Barros Barreto.

Universidade Federal do Pará

Instituto de Filosofia e Ciências Humanas/Faculdade de Psicologia

Av. Augusto Correa, 1- Guamá

66075-110 Belém, PA, Br.

brenopena@hotmail.com

https://orcid.org/ 0000-0003-4485-3673

\section{Jacqueline de Oliveira Moreira}

Professora da Pós-Graduação em Psicologia da Pontifícia Universidade Católica de Minas Gerais - PUC-Minas (Belo Horizonte, MG, Br). Doutora em Psicologia Clínica pela Pontifícia Universidade Católica de São Paulo - PUC-SP (São Paulo, SP, Br). Mestre em Filosofia pela Universidade Federal de Minas Gerais - UFMG (Belo Horizonte, MG, Br). Psicanalista. Bolsista Produtividade CNPq PQ2. Membro do GT da ANPEPP "Psicanálise, Clínica e Política". Membro da Comissão de Propostas Socioeducativas 
do Fórum Permanente do Sistema Socioeducativo de Belo Horizonte. Projeto Aprovado APQ-02862-17 - Edital Universal FAPEMIG.

Rua Congonhas, 161 - São Pedro

30330-016 Belo Horizonte, MG, Br

jackdrawin@yahoo.com.br

https://orcid.org/0000-0003-0901-4217

\section{Andréa Máris Campos Guerra}

Professora Associada do Departamento de Psicologia e do Programa de Pós-Graduação em Psicologia da Universidade Federal de Minas Gerais - UFMG (Belo Horizonte, MG, Br), Bolsista Produtividade CNPq PQ2, Projeto Aprovado pelo Edital Universal 01/17 da FAPEMIG. Coordenadora do Núcleo PSILACS da UFMG (Psicanálise e Laço Social no Contemporâneo), membro do GT da ANPEPP Psicanálise, Clínica e Política, do Coletivo Amarrações, da REDIPPOL (Psicanálise e Política), da Comissão de Propostas Socioeducativas do Fórum Permanente do Sistema Socioeducativo de Belo Horizonte, Psicanalista.

Universidade Federal de Minas Gerais - FAFICH

Av. Antônio Carlos, 6627 - Pampulha

31270-901 Belo Horizonte, MG, Br andreamcguerra@gmail.com

https://orcid.org/0000-0001-5327-0694

This is an open-access article, which permits unrestricted use, distribution, BY-NC and reproduction in any medium for non-commercial purposes provided the original authors and sources are credited. 